Article

\title{
An Experimental HBIM Processing: Innovative Tool for 3D Model Reconstruction of Morpho-Typological Phases for the Cultural Heritage
}

\author{
Vincenzo Barrile *, Ernesto Bernardo and Giuliana Bilotta
}

check for updates

Citation: Barrile, V.; Bernardo, E.; Bilotta, G. An Experimental HBIM Processing: Innovative Tool for 3D Model Reconstruction of Morpho-Typological Phases for the Cultural Heritage. Remote Sens. 2022, 14, 1288. https://doi.org/10.3390/ rs14051288

Academic Editors: Domenico Visintini and Filiberto Chiabrando

Received: 31 January 2022

Accepted: 3 March 2022

Published: 6 March 2022

Publisher's Note: MDPI stays neutral with regard to jurisdictional claims in published maps and institutional affiliations.

Copyright: (C) 2022 by the authors. Licensee MDPI, Basel, Switzerland. This article is an open access article distributed under the terms and conditions of the Creative Commons Attribution (CC BY) license (https:// creativecommons.org/licenses/by/ $4.0 /)$.
Dipartimento Ingegneria Civile, Energia, Ambiente e Materiali-DICEAM, Laboratorio di Geomatica, Università Mediterranea di Reggio Calabria, 89122 Reggio Calabria, Italy; ernesto.bernardo@unirc.it (E.B.); giuliana.bilotta@unirc.it (G.B.)

* Correspondence: vincenzo.barrile@unirc.it

\begin{abstract}
In this paper, we want to propose an investigation and a re-reading of the "Conventazzo" of San Pietro di Deca in Torrenova (ME), through the use of geomatics techniques (laser scanner, UAV-Unmanned Aerial Vehicle-photogrammetry and BIM-Building Information Modeling) and a reconstruction and representation of different morpho-typological phases that highlight the numerous changes that this structure has undergone over the years. Particular attention was given to the BIM/HBIM (Heritage BIM) construction, bearing in mind that, in particular, the use of HBIM software for cultural heritage cannot perfectly represent old buildings with complex notable and particularly detailed architecture. Specifically, a new methodology is presented in order to replicate the complex details found in antique buildings, through the direct insertion of various 3D model parts (.obj) (point cloud segmentation from laser scanner and UAV/photogrammetry survey) into a BIM environment that includes intelligent objects linked to form the smart model. By having a huge amount of information available in a single digital model (HBIM), and by including all the information acquired during the survey campaign, it is possible to study the morphotypological evolutions of the building without the need to carry out subsequent survey campaigns. The limit of the proposed methodology, compared to the most used methodologies (despite the good results obtained), is that it requires the use of many types of software and is very slow. The proposed methodology was put to the test on the reconstruction of the "Conventazzo" in San Pietro di Deca, Torrenova (Messina).
\end{abstract}

Keywords: HBIM; BIM; photogrammetry; UAVs; laser scanner; 3D segmentation

\section{Introduction}

As known, HBIM is currently widely used and provides great potential for the representation of the cultural heritage (managing and documenting historical buildings) in Italy as well as the various restoration activities carried out allowing information to be associated with all the details of the structure and providing the following benefits, which are listed below:

- The ability to save historical documents.

- The ability to collect all data in a single package.

- The ability to assist with technical analysis.

- The ability to contribute to the organization and strategy of restoration and conservation projects.

- The ability to plan interventions for maintenance (BIM can store maintenance info for each construction component in a data repository).

- The ability to promote cultural heritage by means of the web-sharing of models or the creation of tools (App.) allowing the visualization of artefacts in augmented or virtual reality. 
- The ability to monitor degradation.

- The ability to simulate structural behavior for preventive purposes, if events (natural or man-made) occur that may compromise its stability.

- The ability to share the $3 \mathrm{~d}$ model created, so that tourists can explore every part of it in real-time during the tour [1].

It is also important to note that in the field of conservation, the HBIM model can contain information relating to the maintenance interventions already carried out and information on the interventions to be carried out in the future (scheduling of maintenance interventions), but it can also keep all related information to the current state of the buildings (such as details, decorations, etc.), which in the event of calamitous events can constitute valuable support for any restorations/reconstructions.

There are many potential approaches to addressing the issue, but they will take a very long time to implement. The absence of common regulation as well as normalized workflows, combined with significant problems in the modeling and information retrieval phases, results mainly in difficult building and reconstruction sequences, in uncertainties about construction methods and in the presence of particular elements that are not contained in the standard libraries.

To date, the method of developing an HBIM model for traditional elements has implicated point cloud "tracing" and inserting parametric objects; it has also involved the application of a morphology software for the modeling of specific shapes.

Nonetheless, those processes are created for new buildings and therefore simple environments and do not take into account complex structures, elements and friezes. As a solution to the problem, the authors used geomatics techniques to obtain, from the appropriately segmented point cloud (representative of the complex object), single-object building elements or friezes, thus creating a smart approach in a virtual environment by importing data "piece by piece". As a result, these "segmented pieces" will be transformed into smart objects, which will then be reconnected within HBIM.

In this regard, the new methodology proposed foresees the direct insertion of parts of the 3D model into a BIM environment (.obj), converting them into smart objects, which are then interrelated to form this same smart model.

This methodology was used at the San Pietro di Deca site.

The following are therefore important:

- The correct use of survey techniques and methodologies (laser scanner/photogrammetry/ UAV) to collect point clouds of the element of cultural heritage to be modelled.

- The use of appropriate methodologies for segmenting and classifying for extrapolation of "the parts" that contribute to making up model. To be transferred subsequently in the HBIM for connectivity and successive physical and material parameterization.

In the proposed experiment, the logic procedure we used in the HBIM building differs from that available in the literature, allowing one to better define the recognition of various "faults" (which distinguish a specific cultural heritage object, ensuring its perfect reproduction and digital survival) but are overall a bit slow and cumbersome and sometimes cause problems regarding interchanging formats.

Moreover, this new procedure made it possible to apply details to the model created and to easily modify it to create new models to appropriately describe all the different morpho-typological artefact phases and thus the changes it has undergone over time.

\section{Materials and Methods}

BIM is a digital representation of building characteristics and information and is a procedure that includes all the phases of a structure's life cycle [2,3]. Due to BIM, who works in the building's life cycle can upload and share data.

This procedure allows for a deep examination of the model's structural and energetic aspects (it's brightness, acoustic, and material aspects, and so on), allowing for the modeling of various scenarios and making these tools indispensable in the procedure of normal and extraordinary building maintenance. It is, in fact, possible to control and track the life of an 
existing building by applying BIM techniques, facilitating the disclaimer of architectural heritage and enhancing both data entry and modeling methods. Because 3D reproduction in a BIM enables a tour of the model via real-time visualization systems [4], end users (for example, municipalities cultural institutions, universities and so on) will be able to access the model in AR and interact with it, by applying theoretical knowledge for improvement. In comparison to the techniques and instruments typically used for new projects, information on existing structures requires one to rethink levels of knowledge, which is frequently hard to detect due to the absence of designs and solid information [5].

Consequently, the existing building survey results (for example, point cloud) are then compared to application object libraries for determining similarity. This process enables the development of lean models, streamlining the data association process for documentary evidence or numerical simulations.

As a result, HBIM is a tool that only concerns existing buildings (as opposed to simple BIM, which is also applied to the design of new buildings) and therefore contains approaches and methodologies to make the information acquired from surveys usable (in the best possible way).

Another method, known as Scan-to-BIM, uses survey-derived geometric components obtained locally rather than relying on precompiled object libraries [6].

The type of data contained in HBIM and the modeling approach type distinguish it primarily from BIM. While BIM assists professionals in coordinating the various stages of construction with the multiple players who integrate their skills into the model (structural, architectural and planting), HBIM emphasizes the significance of knowledge concerning the state of conservation of materials and places, thereby providing conservators, managers, designers and others with a specific tool for assisting regular monitoring and restoration analyses. As a result, it is indeed obvious that the primary phases of HBIM are investigation and modeling, to complete one's understanding of the historical artifact. The following is a summary of how an HBIM model is implemented:

- Data collection from various technologies;

- $\quad$ Point cloud generation;

- Import and modify point clouds for semi-automatic recognition in a BIM environment;

- Semi-automated BIM element generation;

- Creating models for the remaining components;

- Connecting all components to produce a complete replica of the artifact.

It is significant to mention that the authors' methodology is not yet capable to create an HBIM model with a single piece of software $[7,8]$ to use integration of various programs, taking full advantage of file formats that allow for transmission while preserving the greatest amount of data possible, in some cases using plugins that interact with the different programs.

Obtaining new clouds of points of cultural heritage artifacts today requires the application of proven methodologies and techniques (photogrammetry and laser scanner) that are distinguished by a precision that can vary greatly depending on the requirements, tools and so on but that is also capable of achieving millimetric accuracy.

For the time being, a point cloud could be used to produce a parametric model with the highest level of accuracy. However, the process takes time to complete (Murphy et al., 2009). In fact, beginning with the building inspection, the procedure must gather as much data as possible before transferring it to a model. However, depending on the purpose of the survey, this procedure varies [9].

Recent research has focused on the improvement of standard processes and automated procedures for carrying out results faster than manual methods. These processes must avoid information and detail loss while requiring more information on the elements' pieces with improved model accuracy in the BIM. The HBIM scanning procedure, in fact, is quick and smooth, reproducing environments free of construction flaws by human error or the structure's age. As previously stated, two primary approaches have been used to date: the first compares the point cloud to existing objects database in libraries, in search of the most 
comparable, while the second uses surface data (clouds of points) to perform [10] another type of classification.

The HBIM procedures are constantly evolving. The most recent studies try to automate HBIM by utilizing libraries, yet it is evident that parametric aspects may not be compatible with cultural heritage. Conversely, the authors propose to divide the elements into subelements to avoid all elements being leveled. This method involves importing 3D model pieces into a BIM and converting them into smart objects that form an intelligent model.

For this purpose, the photogrammetry or laser scanner point clouds were segmented for extrapolating and classifying the "pieces" that comprise the model, and the "pieces" were then imported in the HBIM to connect and, finally, match parameters, whether material or physical. Notably, the logical process employed here differs significantly from others investigated in literature. Nonetheless, despite the fact that it speeds up the procedure, this process highlights difficulties with multiple software and file formats.

The authors' procedure is depicted in Figure 1.

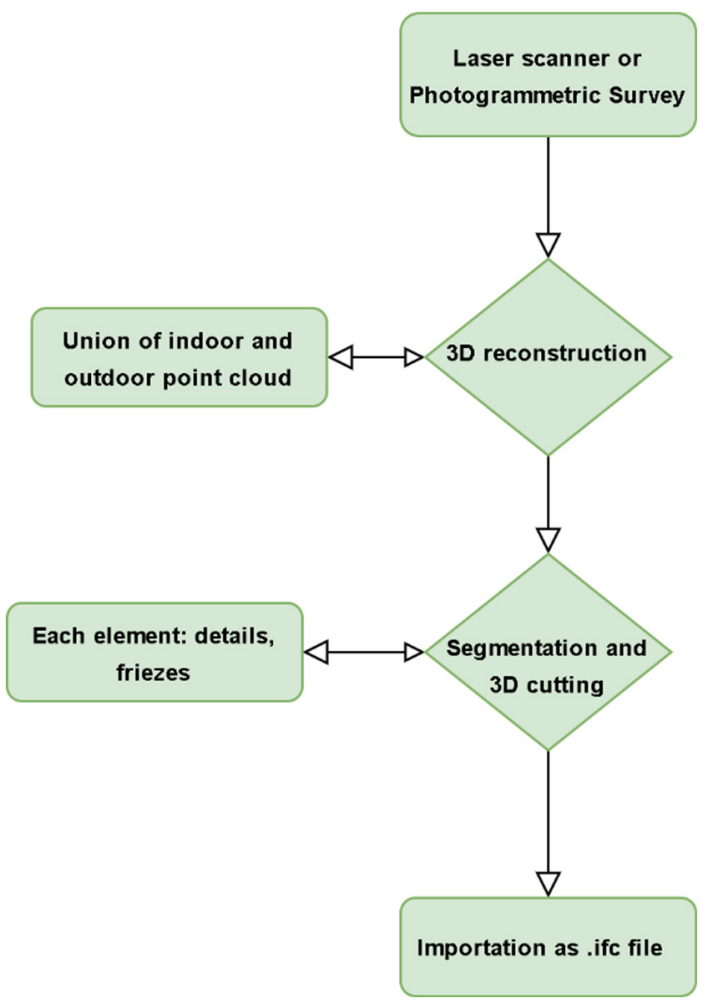

Figure 1. Reconstruction, segmentation and import procedure.

As a result, we could construct a logical and congruent model in which most of the data are stored in a software database. Laser scanner and photogrammetric surveys were used. To proceed with 3D reconstruction, we conducted a case study. We used a DJI Mavic Phantom 2 UAV, a Nikon D750 reflex and a FARO Focus 3D X 130 laser scanner in order to obtain the digital image set of data needed for 3D photogrammetric reconstruction of interiors and exteriors.

Technical features of the DJI Phantom 2 are 14 Megapixel camera for quality photos and videos up to 1080p; $2.4 \mathrm{GHz}$ Wi-Fi for smartphones via smartphone; app for iOS and Android included to control and monitor the drone in real time; controller equipped with smartphone holder; intelligent orientation control; support dual-flight control mode; up to 25 min of continuous flight; autopilot and return home function if low on battery (via GPS coordinates); LED indicators; and low-voltage protection.

Technical features of the Nikon D750 reflex are 24.3 megapixels; professional imaging technology; newly designed FX-format sensor; extremely sensitive AF performance; burst- 
shooting speed up to $6.5 \mathrm{fps}$; Full HD movie recording at 1080/60p; tilting monitor; and built-in Wi-Fi.

Technical features of Focus 3D X130 with Range Focus 3D X130 are 0.6-130 m; measurement speed up to 976,000 points/second; linearity error $\pm 2 \mathrm{~mm}$; integrated color camera up to 70 million pixels; laser class 1 ; weight $5.2 \mathrm{~kg}$ GPS multi-sensor; compass; height sensor; dual axis compensator; dimensions: $240 \times 200 \times 100 \mathrm{~mm}$; and scanner control: via touchscreen display and WLAN.

\section{Data and Results}

\subsection{Case Studies}

The Conventazzo (Figure 2) was used to test the authors' methodology.

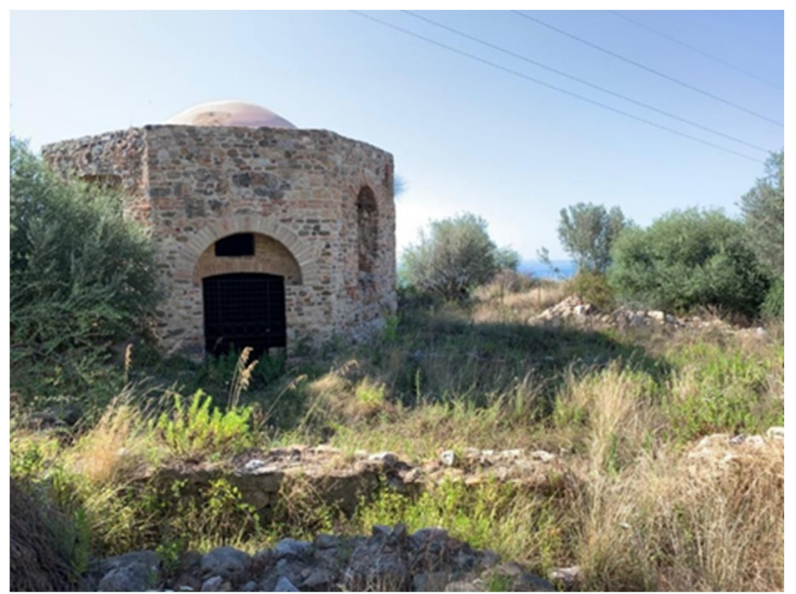

Figure 2. The sacred complex of San Pietro di Deca.

Of the sacred complex (Basilian Monastery), which rests or reuses previous structures, there remains a singular octagonal plan structure covered by a hemispherical dome (San Pietro di Deca in the official toponymy and "Conventazzo" in the demotic of the place), whose original construction precedes that of the Basilian monastery. The basic term is convent (cum coming - cum ventum = meeting), with an augmentative alternative suffix. Probably, the literary alteration intends to express the idea of decay, representing the state that the factory was in. Obviously, the term cannot refer only to the "baptistery" but clearly also refers to the entire architectural compendium, abbey and baptistery. All the scholars who have dealt with the Conventazzo unanimously date its origins to the late ancient age (4th/5th century AD) and see its original function either as a commemorative monument (cenotaph) or, less likely, as a part of a spa complex. The Christian use, possibly, but not yet proven, as a baptistery, took over at a later time; however, it was durable and effectively guaranteed the survival of the building. In fact, it was incorporated, around 1100, into the now disappeared monastic complex of San Pietro di Deca, to whose existence its traditional name, Conventazzo, precisely refers (Figure 3).

The eight elevations have undergone numerous changes over the centuries, and each is distinguished by the presence of opening, single-lancet windows that appear to intercept mullioned windows, which have now been partially or completely canceled. The entrance is located in the south-east elevation and leads into a circular environment that circumscribes a large space characterized by seven apses with brick archways that are all placed at the same height along the walls. Each apse was most likely frescoed, both in the basin and in the apse basin. Only a few traces of plaster remain today. The construction technique is characterized by irregular assizes of various local stones and bricks. We occasionally come across well-squared ashlars, a clear indication of the presence of reused material from neighboring structures that have partially or completely vanished. 


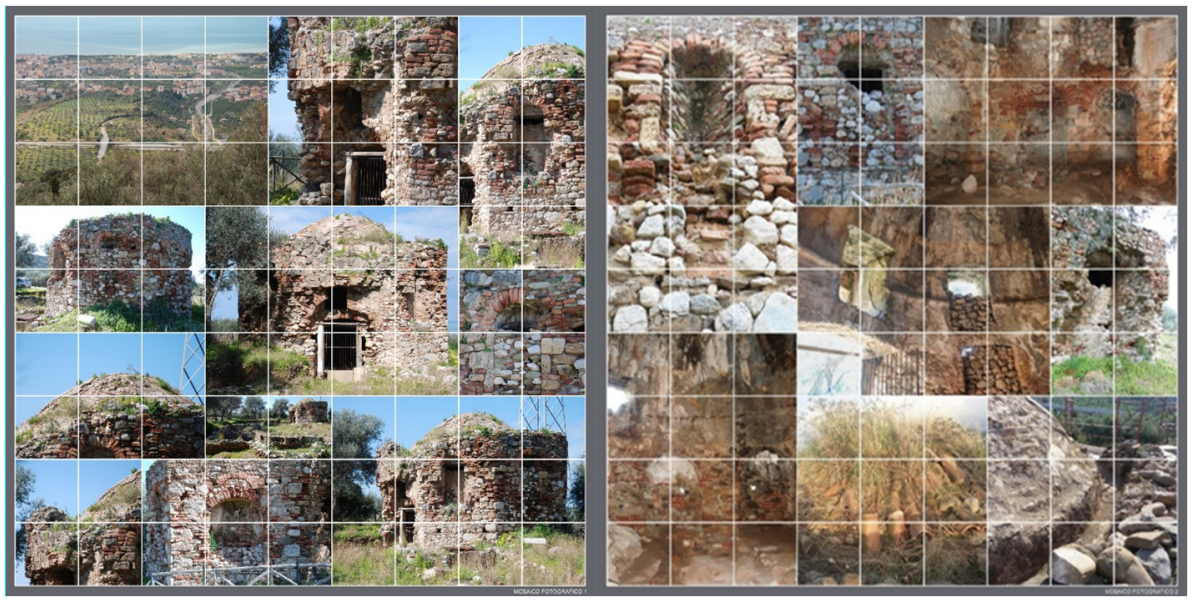

Figure 3. Photo-mosaic survey.

\subsection{Model 3D Reconstruction}

This Conventazzo parametric model was built using internal and external photogrammetry/UAV/laserscanner/Reflex surveys.

For the exterior survey, a DJI Mavic Phantom 2 UAV and a Nikon D750 reflex were used, then we used the georeferenced photographic data set acquired to build a first $3 \mathrm{~d}$ model of the exterior using the classic Agisopht Metashape software.

The external 3D models obtained with a UAV and Reflex survey are represented in Figure 4.

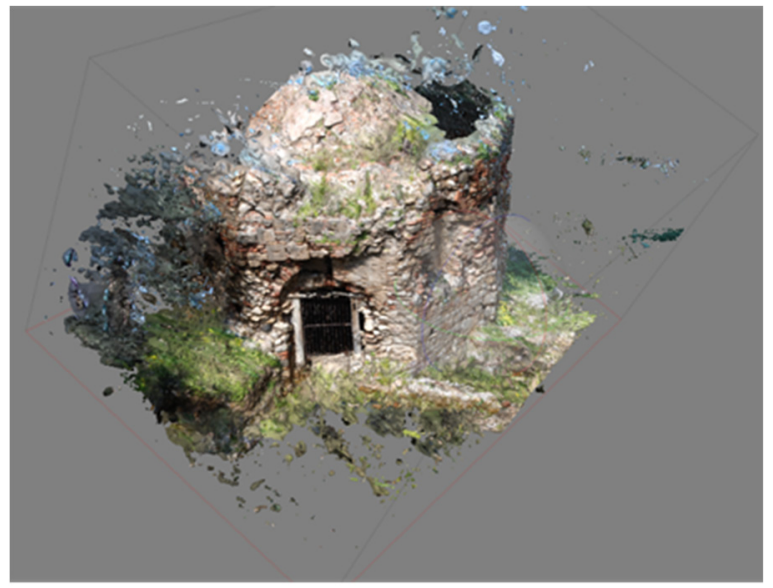

Figure 4. External 3D models obtained with a UAV and Reflex survey.

Later, a Faro 3D X130 laser scanner and the commercial program FARO scene v.4.1 were used. Software [11,12] was used for the survey of the interior and exterior in classic mode. Then, we proceeded to integrate the point clouds acquired externally and internally by the laser scanner, obtaining the image in Figure 5 overall of the whole area.

Figure 5 shows the points where we placed the laser scanner for the surveys.

The survey with the laser scanner made it possible to obtain floor plans for some elevations and sections in Figures 6 and 7:

In order to calculate the thicknesses of the walls and the dome, it is necessary to have a survey of the interior and exterior. Since the 3D model obtained by integrating the interior and exterior from the laser scanner survey did not include the upper part of the dome, it was necessary to integrate the first model obtained from the UAV + Reflex survey with the model obtained from the laser scanner [9]. 


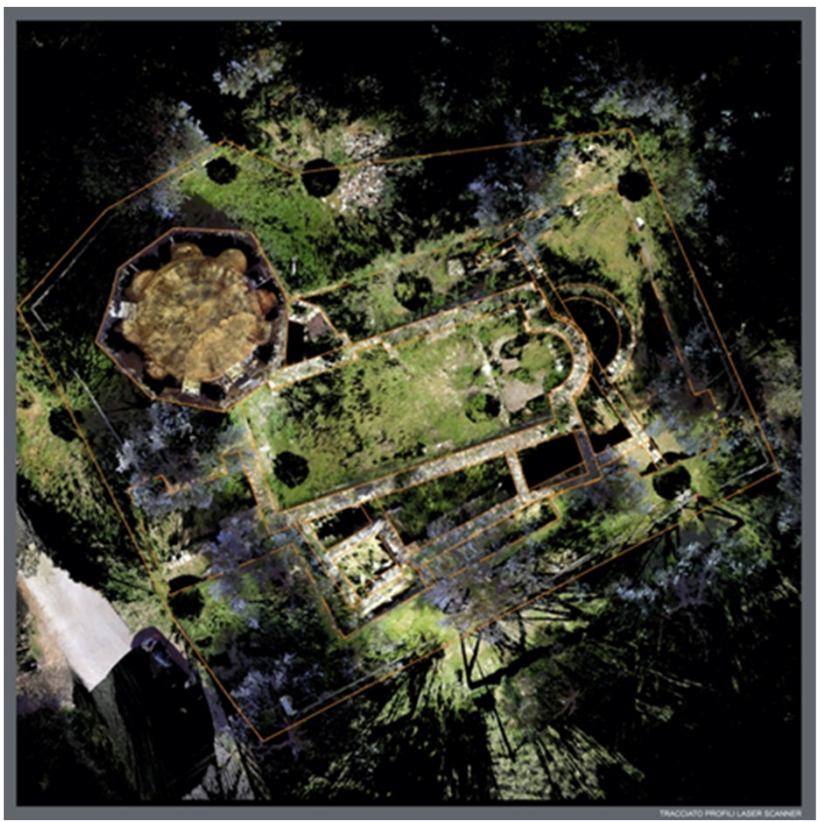

Figure 5. Points where the laser scanner was placed to carry out the surveys.
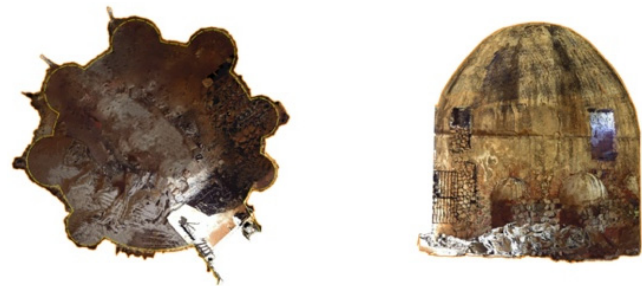

Figure 6. Internal survey with laser scanner.

Table 1 demonstrates comparisons $\left(\Delta_{\mathrm{RP}} \Delta_{\mathrm{RL}}\right)$ and precision between real measurements $(\mathrm{R})$ of various elevations $(\mathrm{L})$ and heights $(\mathrm{H})$ of the Conventazzo and measurements derived from the 3D models created with photogrammetry and laser scanners. The difference in measurements and relative accuracy, as expected, highlights the greater dependability of the laser scanner technique. Therefore, in the following phases, leaving aside the point cloud derived from the drone, the point cloud derived from the laser scanner was employed.

Real measurements were acquired with medium-to-high precision instrumentation (Leica SmartStation with integrated GNSS receiver). The point clouds were combined using the ground control points (GCP) recorded in this way as a reference.

As result of the point clouds' union and registration, we were capable of accurately identifying (millimetric precision) the thickness and shape of slabs and floors throughout all of their extensions. Figure 8 shows a screenshot of Autodesk ReCap's "tour" between the two point clouds.

\subsection{HBIM Reconstruction}

In this specific case, we are dealing with the HBIM implementation of a historical building; as highlighted above, all of the issues raised in the preceding paragraphs (actual modeling difficulties, irregular sections of the walls with unknown stratigraphists and architectural details) are present $[13,14]$.

As a result, in order to obtain a BIM that is as close to the architecture of the original historical building as possible while preserving the presence of the original defects and the diversity of the forms that comprise it, the methodology presented below was used. 


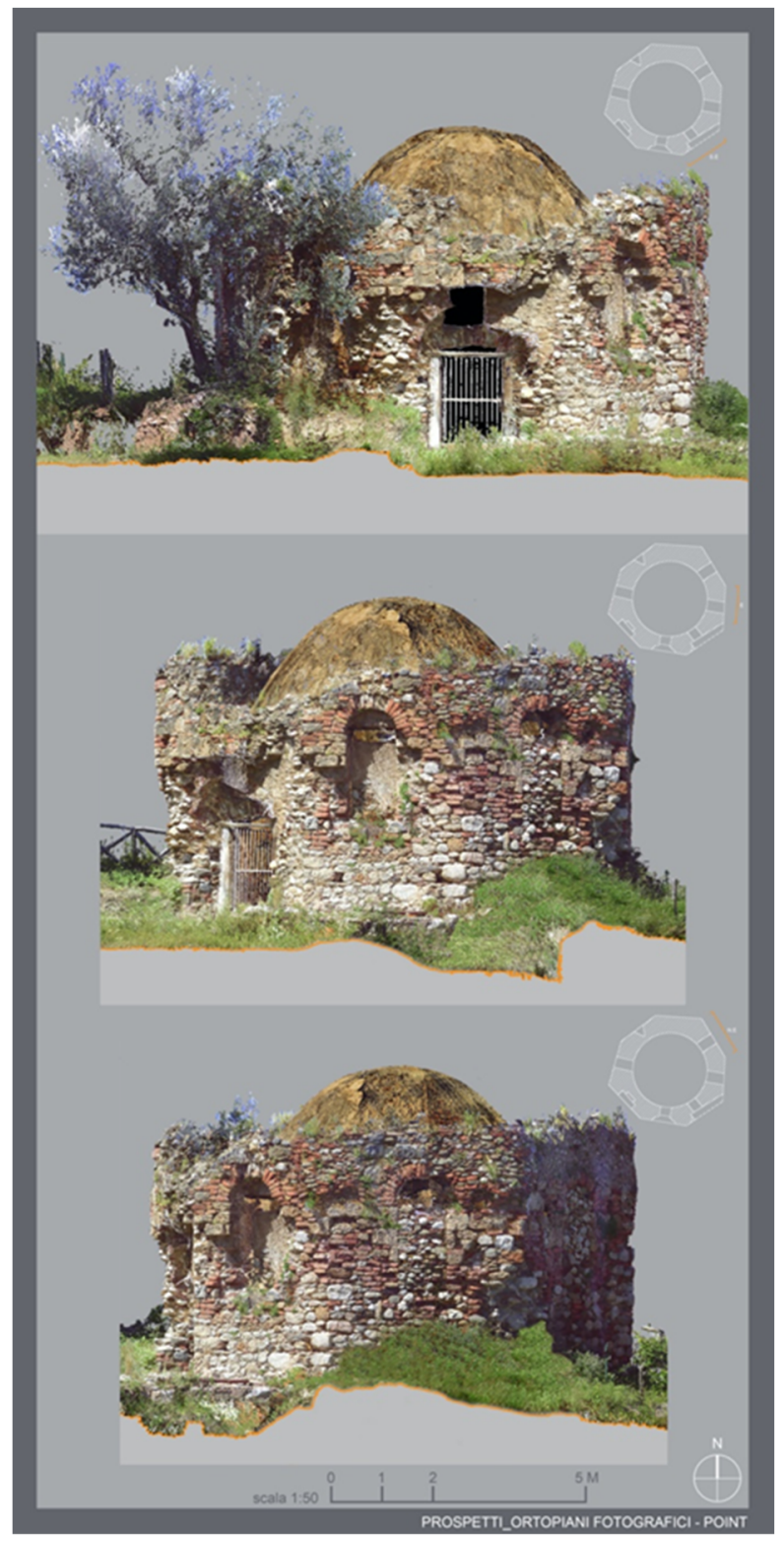

Figure 7. Survey with laser scanner.

Table 1. Comparisons $\left(\Delta_{\mathrm{RP}} \Delta_{\mathrm{RL}}\right)$ and precision between real measurements (RM) of widths (W), internal and external heights $(\mathrm{H})$ of the principal external walls $(\mathrm{N}, \mathrm{S}, \mathrm{E}, \mathrm{W})$, and height of dome and some measurements derived from the 3D models created with photogrammetry and laser scanners.

\begin{tabular}{|c|c|c|c|c|c|c|}
\hline Elements & $\begin{array}{c}\text { Real } \\
\text { Measurement (RM) }\end{array}$ & $\begin{array}{c}\text { Photogrammetric } \\
\text { Measurement }\end{array}$ & $\begin{array}{l}\text { Laser Scanner } \\
\text { Measurement }\end{array}$ & Points & $\Delta_{\mathrm{RP}}$ & $\Delta_{\mathrm{RL}}$ \\
\hline W. E & 4 & 3.9 & 3.95 & 2 & 0.1 & 0.05 \\
\hline W. N & 3.7 & 3.8 & 3.8 & 4 & 0.1 & 0.1 \\
\hline W. W & 3.9 & 4 & 3.87 & 6 & 0.1 & 0.03 \\
\hline W.S & 3.9 & 4 & 3.87 & 7 & 0.1 & 0.03 \\
\hline H. S & 5.76 & 5.8 & 5.8 & 8 & 0.04 & 0.04 \\
\hline H. E & 4.98 & 5 & 5 & 9 & 0.02 & 0.02 \\
\hline H. N & 5.01 & 5.2 & 5 & 11 & 0.19 & 0.01 \\
\hline H. W & 4.54 & 4.64 & 4.6 & 13 & 0.1 & 0.06 \\
\hline H. internal & 6 & 5.9 & 5.96 & 16 & 0.1 & 0.04 \\
\hline H dome & 7.7 & 7.6 & 7.65 & 17 & 0.1 & 0.05 \\
\hline
\end{tabular}




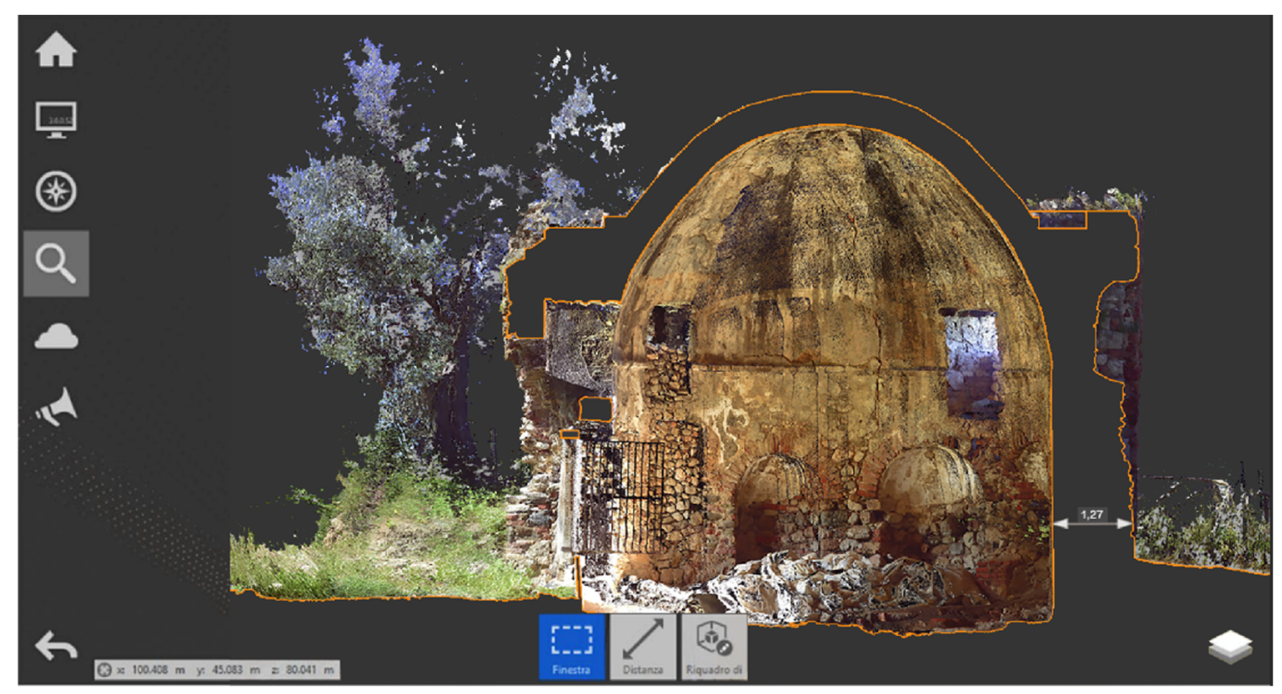

Figure 8. Conventazzo. Union of point clouds.

The technique is based on the direct incorporation of various 3D model parts (.obj) in a BIM, where they are transformed into interconnected smart objects that form a smart model. For this purpose, the drone/laser scanner point clouds were segmented for extrapolating the pieces to be imported into HBIM; interconnected; and then physical and material parameters were assigned.

Regarding the segmentation step, it should be noted that point cloud analysis is still in its early stages, and there are currently various techniques and algorithms to deal with this type of data [15]; point cloud segmentation and categorization are hot research issues. As is well known, the division of point cloud into many homogeneous sections (radiometric, geometric, etc.) is known as segmentation, whereas classification is the definition and assignment of points to specific classes, known as "labels", based on different criteria. These two processes allow relevant information to be extracted from acquired data. Debugging, spatial analysis and object simplification are also active research areas.

To extract useful information from the point cloud, the affected objects in the captured scene must be segmented and classified. Many research studies have been conducted on these two topics, which are motivated by the specific needs provided by the field of application (cultural heritage, building modeling, heritage documentation, robotics, etc.). Özdemir and Remondino present a non-exhaustive review of segmentation and classification methods [16].

Edge-detection algorithms are used in edge-based segmentation to delineate the edges of various regions and group points within boundaries to provide final segments.

Model fit segmentation assumes that many man-made items may be reduced to geometric primitives.

Finally, algorithms of machine learning generally perform classification, which is the foundation of AI methods (including neural networks, deep learning). Computer vision includes machine learning that employs artificial intelligence algorithms to allow computers to make data-driven decisions, based on trained and empirical data.

The classification of segmented points can be accomplished in three ways:

- The supervised approach is used to classify the full dataset by learning semantic categories from an annotated data set and the trained model.

- There is an unsupervised approach in which data is automatically segmented by user-supplied algorithm parameterization.

- There is an interactive approach in which the user actively participates in segmentation/classification. 
The flow diagram in Figure 9 describes the process for the extrapolation of the "pieces" that comprise the model, beginning with the point cloud acquisition phase performed by the drone [17]. Figure 10 shows the results.

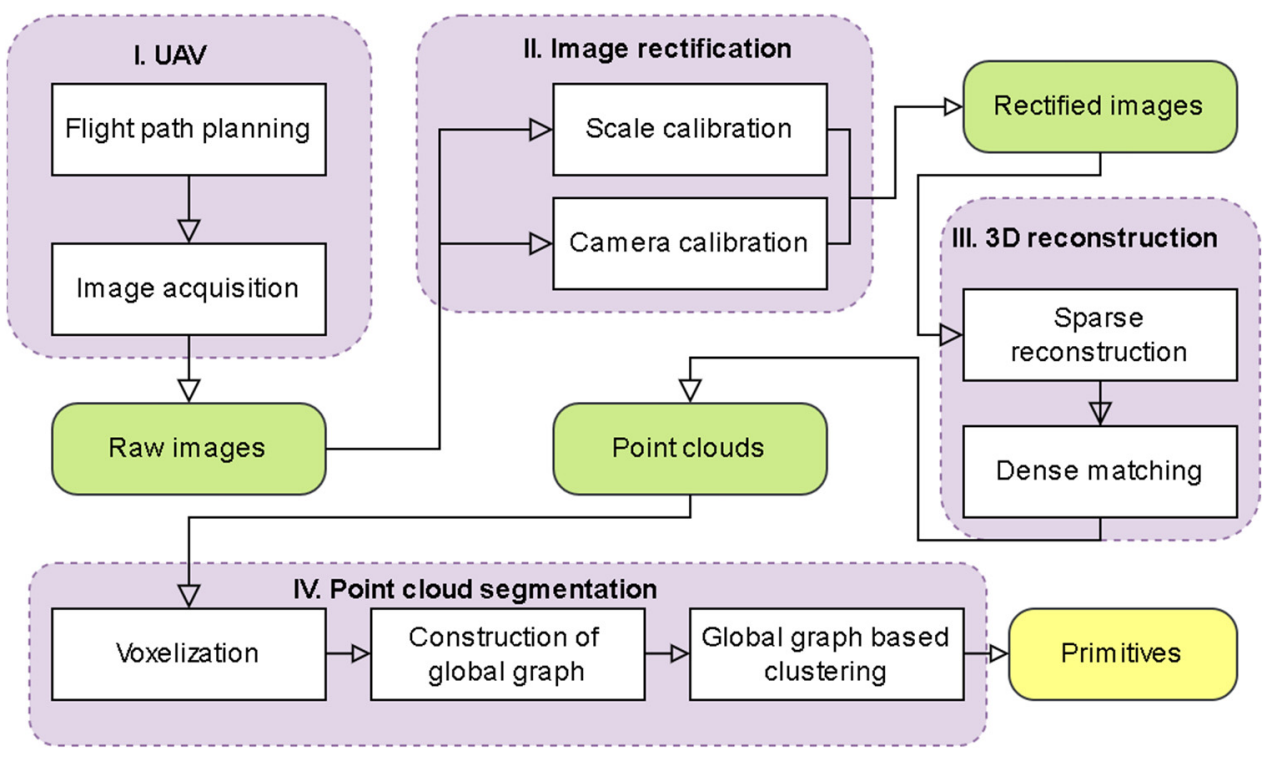

Figure 9. Flow chart of dense cloud (by UAV) segmentation.

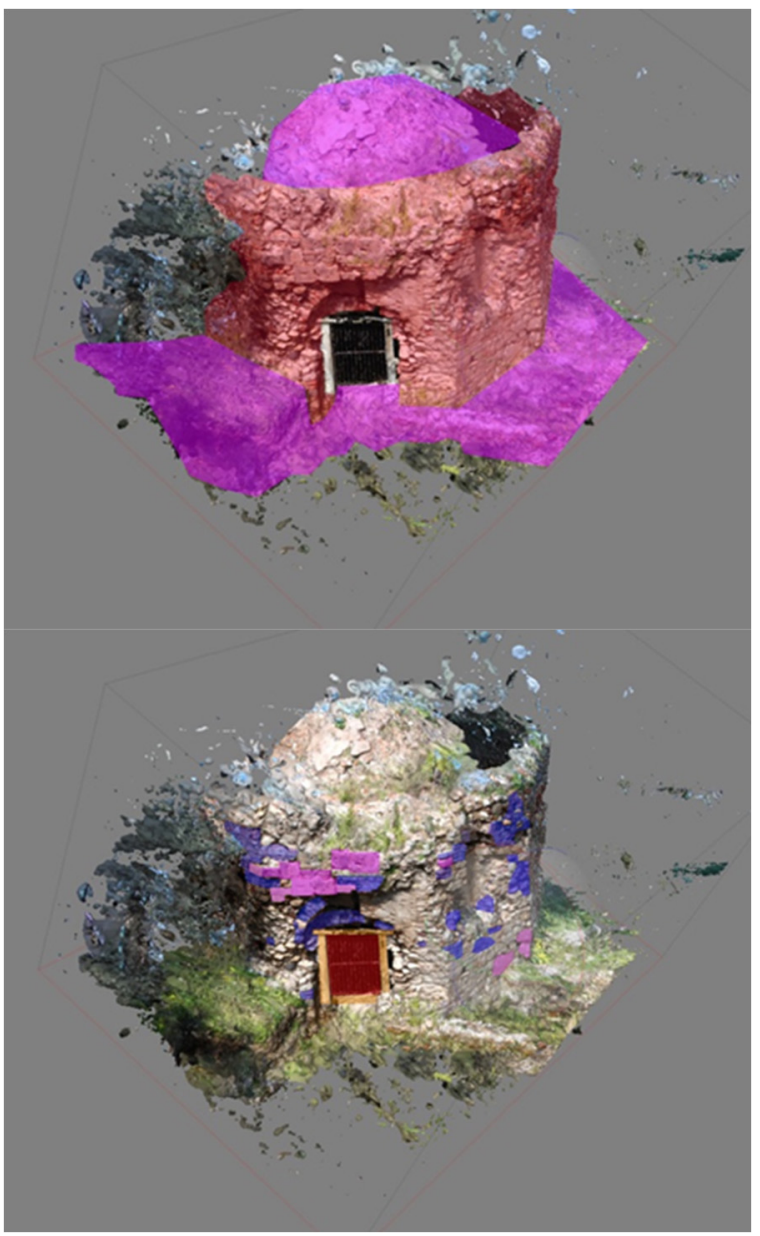

Figure 10. Cont. 


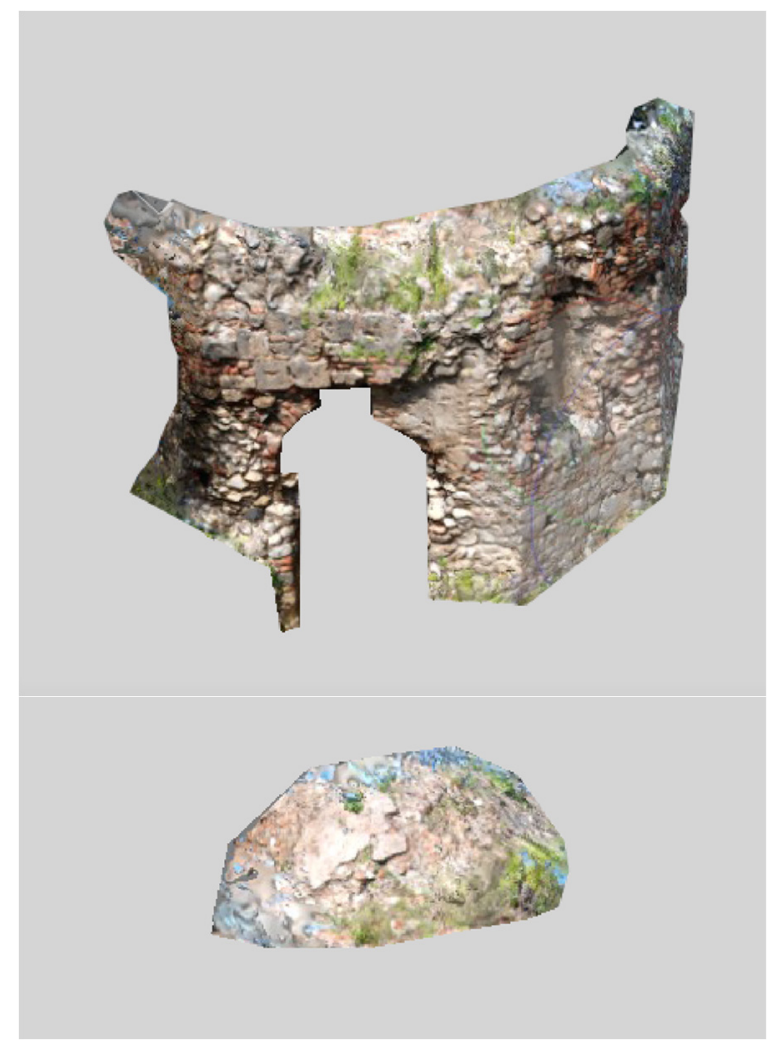

Figure 10. Results of segmentation using reference data.

In relation to the segmentation phase of the point cloud necessary to extract the parts of interest, as explained in the diagram, a technology was used that includes voxelization, construction of global graph, global graph-based clustering, and .obj primitives that can be imported into the BIM software (EDIFICIUS) [5,18-20]. The software processes the segmented and categorizes point clouds to create meshes and 3D models in .obj format.

The obj file is then imported directly into the BIM software in a classic, manual manner. Thanks to this method, we obtained detailed 3D models of the most complex parts, which is not possible with traditional tools.

Alternatively, it is possible to proceed directly by cutting the 3D model resulting from the entire point cloud, obtaining the "pieces" that form it from the model, for extrapolating the "pieces" that form it. As a result, the 3D model is "cut" into numerous elements imported into BIM software (Autodesk Revit) as an .obj file, with the whole cloud guiding the placement of the objects (Figures 11-13).

The methodology used involves the division into parts using cutting plans (Fusion 360 software was used in this instance).

The "Mesh" software workspace finds 3D mesh models such as .stl and .obj, and the models were sectioned using a subdivision command (Plane Cut). It is possible to modify mesh formats and cutting the model using the free Meshmixer software, with different commands working on the files stl and .obj. The most important of these combines two instructions, Plane Cut + Separate shells, to section our models.

After obtaining the objects (in .obj format), they can be made smart by being given certain features and indicating neighboring object connectivity in a standard manner. These .objs were imported with semantic information, such as dimensions and materials, and then placed into the BIM as "families", or groups of similar objects. Metadata enrichment is also available. 


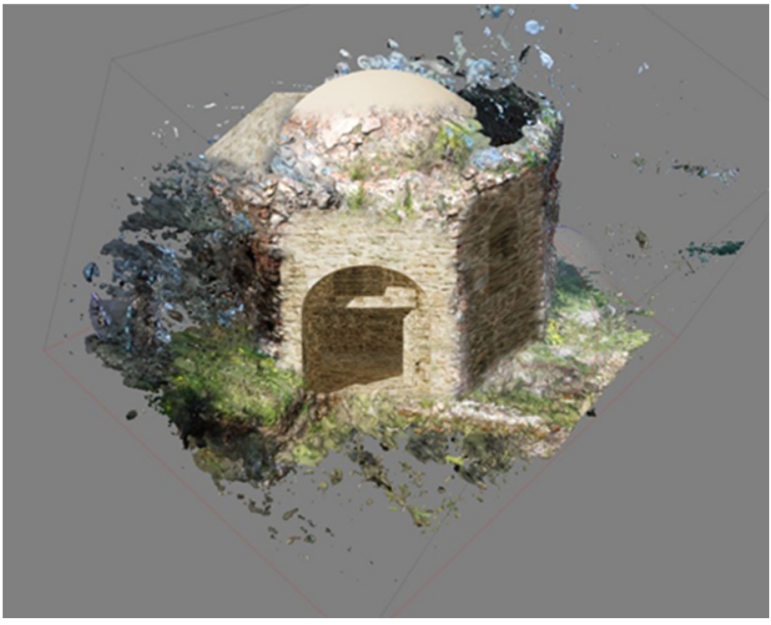

Figure 11. Overlap between BIM and dense cloud.

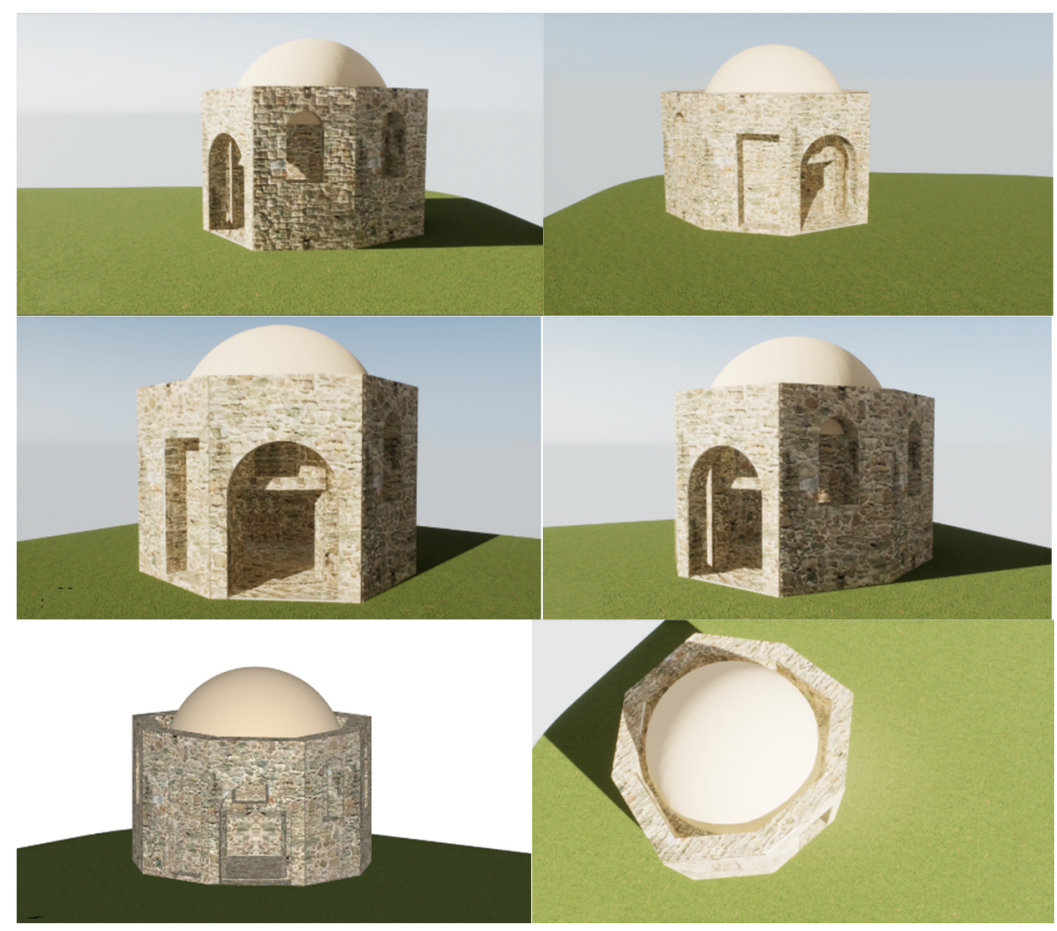

Figure 12. Reconstruction of Building Information Modeling.

This process ensures a material and geometric aspect closer to actual component conformation while simultaneously assuring information management (Barrile et al., 2019b).

Result is the positioning of the objects in space using the point cloud obtained as a guideline [21-24].

For each element, the database has been enhanced by incorporating data from various sources (geometrical information, material descriptions, cadastral data, historical information, maintenance interventions and presence of constraints) into the same DB, which becomes integrated into part of the model [25-27].

It is possible to save the model as an .ifc file and share it across operators to ensure interoperability (a key feature of HBIM/BIM).

Each item contains data on the construction elements' classification: the identifier of the object, the type of renovation cycle, the structural loads, etc. 

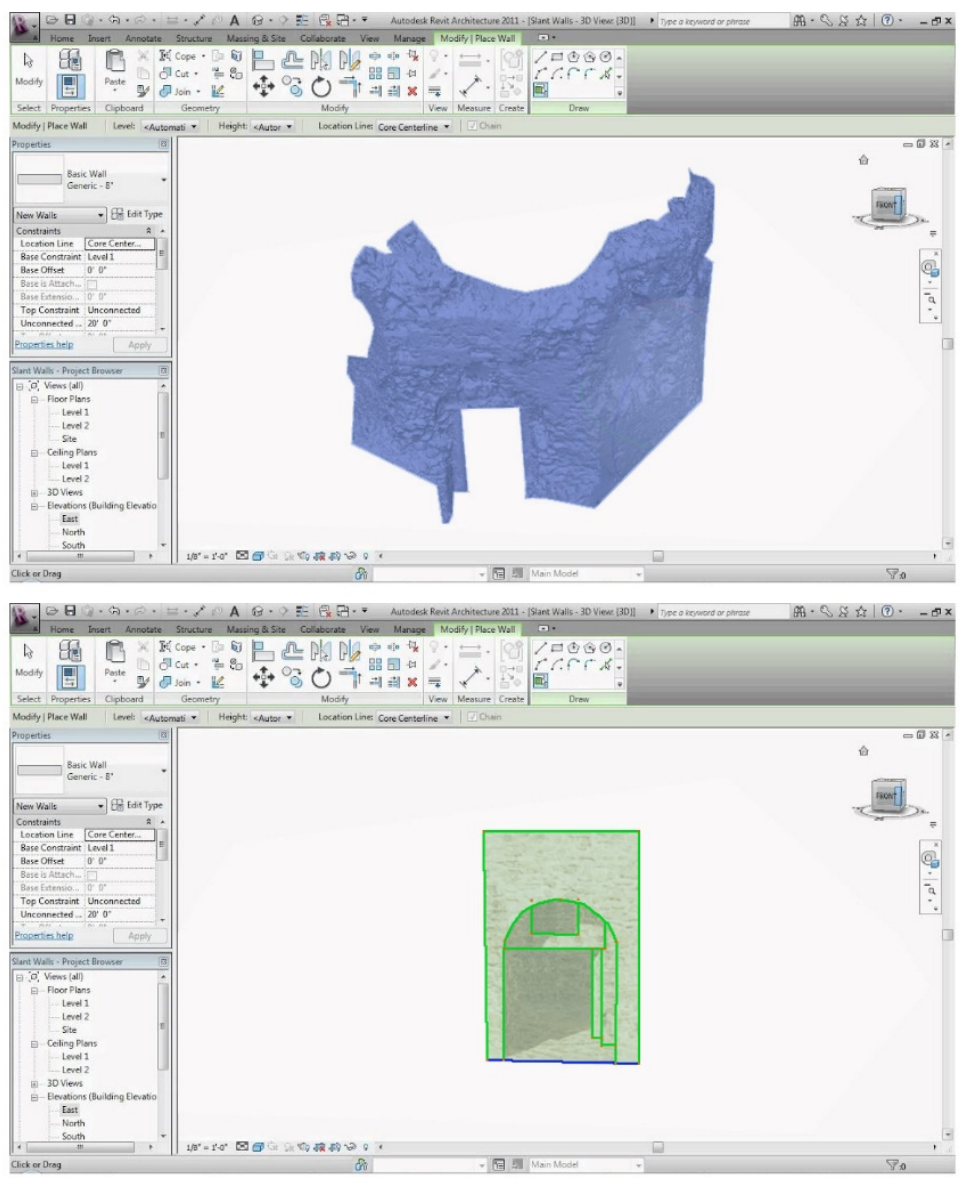

Figure 13. Example of single element's reconstruction on Building Information Modeling.

These are attributes that can be filled out and assigned values. As a user-defined attribute, the information contained in the object can later be converted into an ArchiCAD property. However, semantic data in ArchiCAD is not simple; some are inherent to a given object type, some are generic and some can also be changed by the user to indicate a specific type of phenomenon associated with the object.

As a result of the final models, HBIM is clearly a reverse-engineering approach on existing buildings, and more realistic modeling of historical buildings necessitates a thorough understanding of the building's characteristics (geometric, material and historical).

Data exchange (between subjects) is critical in the BIM method. The open .ifc format (namely, Industry Foundation Classes) enables knowledge sharing.

\subsection{Morpho-Typological Evolutions}

The periodization of the various construction phases described derives in part from the study of the state of the art (archaeological research, previous surveys and scientific publications) and in part from the proposed methodology. Thanks to the experimental methodology used, in fact, having a huge amount of information available in a single digital model (HBIM), including all the information acquired during the survey campaign, it is possible to study the morpho-typological evolution of the building without the need to carry out subsequent survey campaigns. We are able to confirm or refute the deductions derived from possible studies of other authors (think, for example, about the classification of similar materials that compose the mullioned or single lancet windows; in a few clicks we can visualize them as objects in the digital model, checking eventual additions/modifications), and we know the precise thickness of the walls (we can also see if additions/modifications have been made such as if doors or windows have been sealed or modified). Therefore, the methodology proposed in this paper represents the most complete tool to investigate 
the reconstruction of complex modifications that a historical building has undergone over the years.

The drone and laser scanner surveys made it possible to carry out an in-depth analysis of the various modifications that this structure has undergone over the years. Starting from these surveys and the study of historical research already carried out on the structure, we were able to reconstruct the various phases and transformations using BIM and the proposed methodologies.

Of all the scholars who have worked on the building, only two have attempted to reconstruct and describe the phases and the relative modifications that have been made over time: Salvatore Giglio and Edward Kislinger. Kislinger agrees with Giglio's thesis on the multi-phase evolution of the building but differs on many points and on the chronology of the various modifications. He considers that there were at least 6 or 7 phases, as follows.

Phase I: original architectural core with a domed vault (phase I), later "lined" with an outer wall (phase II). It is not possible to say with certainty whether the monument already had its octagonal external shape in Phase I or whether it was rather circular as in the interior. The different lengths of the individual outer walls and the lack of parallelism of the faced sides of the octagon, however, speak in favor of a central, circular plan that was later transformed into an angular one, perhaps due to static problems. We can assume that the transformation of the original circular plan into an octagonal one took place already in the Early Byzantine period.

Phase II: the wall lining of Phase II was not yet as high as it is today. A strip of rectangular square blocks ran above the double lancet windows that decorated the outer walls at that time; the dome was grafted onto this strip, and its convexity was still clearly visible.

Phase III: it was not until Phase III that the outer walls were raised to their present level and the façade was modified. Rectangular single lancet windows crowned by an arch replaced the old double lancet windows underneath, the lower parts of which were closed with a crude filling of stones. Also in Phase III, niches were excavated inside the building. It is no coincidence that they were excavated after the addition of the lining, which caused the walls of the octagon to become thicker. Both the mullioned and single lancet windows were initially purely decorative elements of the outer façade, not real windows opening into the interior. This did not occur until Phase IV.

Phase IV: during this phase, the single lancet windows were changed into shorter but also rectangular windows. That the window was shortened can be deduced from the examination of the lower edge of the new windows on the inside. The remaining part of the single lancet windows on the outer side, up to the terminal arch, was 'bricked in' and filled with stone.

Phase V: during Phase V, the octagon was joined to the monastery church, which resulted in major changes to the south-eastern side of the building. The wall "lining" was removed here up to the height of the church wall, and the eighth niche was opened to form the entrance, as it still does today. Perhaps at this stage, the window on the north-western side (opposite the entrance to the building) became a splayed opening to the outside.

Phase VI: some of the windows were walled up again during Phase VI.

Phase VII: the remodeling of the south-west side finally took place. A large niche, probably intended to hold a votive statue, replaced the mullioned windows, the single-light window and the rectangular window of the previous phases. All subsequent changes made to the convent, such as the reopening and closing of some windows by rudimentary means, were not dictated by architectural or aesthetic requirements but were in response to the needs of shepherds who used the building as a shelter from the weather from around the 18 th century onwards.

This is shown in Figures 14 and 15. 


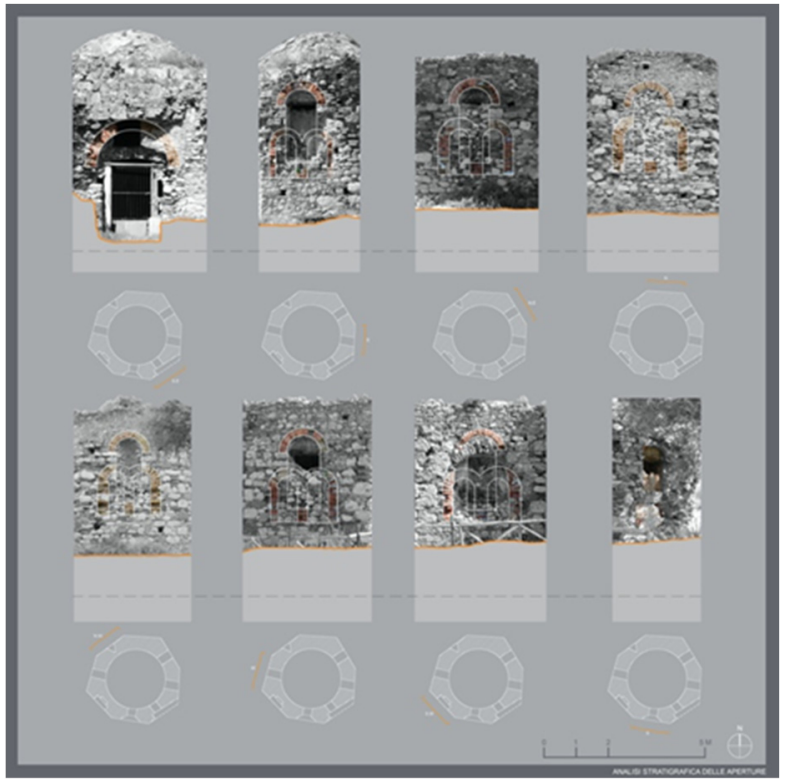

Figure 14. Stratigraphic analysis of openings.

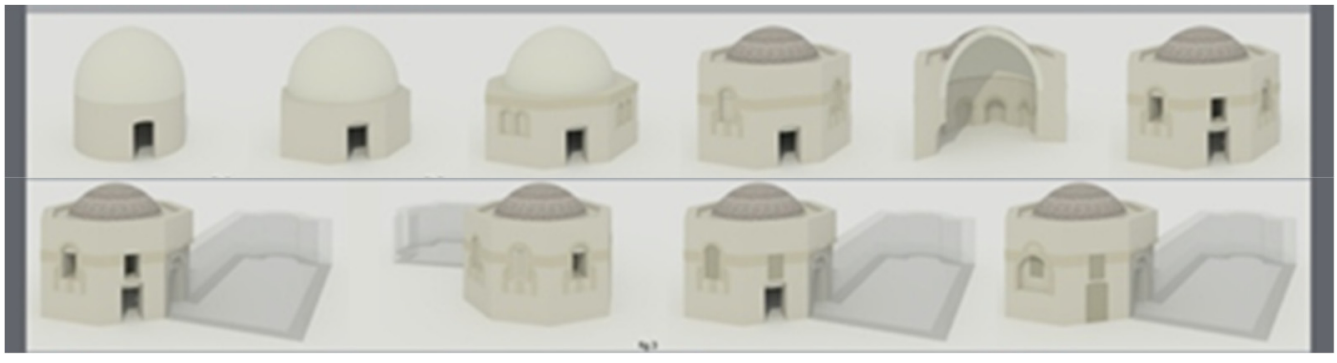

Figure 15. Morpho-typological evolutions (Phases I to VII).

\section{Discussion}

BIM is a method for creating and managing a digital model of a construction project, containing all of its characteristics. It is ideal for modeling geomatics-generated point clouds such as photogrammetry by UAVs. Various types of software have been developed in recent years to view BIM files with the iff extension. The majority of these iff viewers allow one to manage BIM models using traditional 3D navigation functions. In order to preserve information and facilitate restoration or partial reconstruction of buildings, BIM models for existing cultural heritage can be rebuilt, particularly in countries such as Italy that have been affected by strong seismic events.

However, because BIM software for sale is no longer designed or suitable for modeling existing structures, in complex construction, this software cannot reliably represent surface features as some details. Inserting a single class seems to be too generic and causes loss of the information that distinguishes historical buildings (e.g., different designs of capitals and columns of the same architectural style). HBIM is a method for optimizing the planning, restoration, reconstruction and management of historical structures.

\section{Conclusions}

The morphotypological reconstruction of the BIM is fundamental; thanks to the experimental methodology used, and having a huge amount of information available in a single digital model (HBIM in Figure 12), as well as all the information acquired during the survey campaign, it is possible to study the morpho-typological evolutions of the building (Figure 15) without the need to carry out subsequent survey campaigns. Of great importance is the method of segmentation and classification used (Figure 10) to construct 
the BIM because it allows us to analyze complex details that would not otherwise emerge from a normal survey (Figure 13).

Historical reconstruction models allow for the building of databases to retain data and facilitate future restoration or partial reconstruction. The authors constructed the HBIM model using a unique methodology.

The entire photogrammetric model is cut into several parts and saved as an ifc file. It is a type of data format suitable for exchanging data without data loss or distortion, thereby facilitating interoperability between various operators. The model's various parts are then rearranged using the point cloud as a guideline. The outcome is measurable when dense cloud is used as a guide for inserting the various "cut" models (which are .ifc files), where there is no metrical deviation.

As a result, the formation of multi-objects necessitates a lengthy period of elaboration, but it is significantly faster if each element of the cultural asset must be precisely modelled.

More work will be done on improving algorithms, for analyzing geometric and color information from complex elements and details of the building. It is also necessary to automate and to simplify the various steps of the processes used for the proposed method as it requires the use of many different software packages and takes a long time. All the data will be stored in structured models using Building Information Modelling (BIM) and Geographic Information Systems (GIS) technologies.

Author Contributions: Conceptualization, V.B., E.B. and G.B.; methodology, V.B. and E.B.; software, V.B and G.B..; validation, V.B. and G.B..; formal analysis, E.B. and G.B. investigation, E.B. and G.B.; resources, V.B., E.B. and G.B.; data curation, E.B. and G.B.; writing-original draft preparation, V.B. and E.B.; writing-review and editing, E.B. and G.B.; visualization, E.B. and G.B.; supervision, V.B. and G.B.; project administration, V.B., E.B. and G.B.; funding acquisition, V.B., E.B. and G.B. All authors have read and agreed to the published version of the manuscript.

Funding: This research received no external funding.

Institutional Review Board Statement: Not applicable.

Informed Consent Statement: Not applicable.

Data Availability Statement: Not applicable.

Conflicts of Interest: The authors declare no conflict of interest.

\section{References}

1. Banf, F.; Fai, S.; Brumana, R. BIM automation: Advanced modeling generative process for complex structures, ISPRS Annals of the Photogrammetry, Remote Sensing and Spatial Information Sciences. In Proceedings of the 26th International CIPA Symposium, Ottawa, ON, Canada, 28 August-1 September 2017; Volume IV-2/W2.

2. Valero, E.; Bosché, F.; Forster, A. Automatic segmentation of 3D point clouds of rubble masonry walls, and its application to building surveying, repair and maintenance. Autom. Constr. 2018, 96, 29-39. [CrossRef]

3. Pocobelli, D.P.; Boehm, J.; Bryan, P.; Still, J.; Grau-Bové, J. BIM for heritage science: A review. Herit. Sci. 2018, 6, 1-15. [CrossRef]

4. Paris, L.; Wahbeh, W. Survey and representation of the parametric geometries in HBIM. Disegnarecon 2016, 9, 12.1-12.9.

5. Barazzetti, L.; Banf, F.; Brumana, R.; Previtali, M. Creation of parametric BIM objects from point clouds using Nurbs. Photogramm. Rec. 2015, 30, 339-362. [CrossRef]

6. Stanga, C.; Hasníková, H.; Previtali, M.; Brumana, R.; Grimoldi, A.; Banf, F. The assessment of the baroque vault construction technique by scan-to-bim process: St. Bernard's chapel in the plasy monastery. Int. Arch. Photogramm. Remote Sens. Spat. Inf. Sci. 2019, XLII-2/W15, 1127-1134. [CrossRef]

7. Pierdicca, R.; Paolanti, M.; Matrone, F.; Martini, M.; Morbidoni, C.; Malinverni, E.S.; Frontoni, E.; Lingua, A.M. Point cloud semantic segmentation using a deep learning framework for cultural heritage. Remote Sens. 2020, 12, 1005. [CrossRef]

8. Oreni, D.; Brumana, R.; Cuca, B. Towards a methodology for 3D content models: The reconstruction of ancient vaults for maintenance and structural behaviour in the logic of BIM management. In Proceedings of the 2012 18th International Conference on Virtual Systems and Multimedia, Milan, Italy, 2-5 September 2012; pp. 475-482. [CrossRef]

9. Martínez-Carricondo, P.; Carvajal-Ramírez, F.; Yero-Paneque, L.; AgüeraVega, F. Combination of nadiral and oblique UAV photogrammetry and HBIM for the virtual reconstruction of cultural heritage. Case study of Cortijo del Fraile in Nijar, Almería (Spain). Build. Res. Inf. 2020, 48, 140-159. [CrossRef]

10. Micheletti, N.; Chandler, J.H.; Lane, S.N. Structure from Motion (SFM) Photogrammetry; Geomorphological Technique; British Society for Geomorphology: London, UK, 2015; Chapter 2, Section 2.2; pp. 1-12. ISSN 2047-03711. 
11. López, F.; Lerones, P.; Llamas, J.; Gómez-García-Bermejo, J.; Zalama, E. A review of heritage building information modeling (H-BIM). Multimodal Technol. Interact. 2018, 2, 21. [CrossRef]

12. Brumana, R.; Oreni, D.; Raimondi, A.; Georgopoulos, A.; Bregianni, A. From survey to HBIM for documentation, dissemination and management of built heritage: The case study of St. Maria in Scaria d'Intelvi. In Proceedings of the 2013 Digital Heritage International Congress (DigitalHeritage), Marseille, France, 28 October-1 November 2013; pp. 497-504. [CrossRef]

13. Barrile, V.; Fotia, A.; Bilotta, G.; De Carlo, D. Integration of geomatics methodologies and creation of a cultural heritage app using augmented reality. Virtual Archaeol. Rev. 2019, 10, 40-51. [CrossRef]

14. Barazzetti, L.; Banf, F.; Brumana, R.; Previtali, M.; Roncoroni, F. BIM from laser scans ... Not just for buildings: Nurbs-based parametric modeling of a medieval bridge. In Proceedings of the ISPRS Annals of the Photogrammetry, Remote Sensing and Spatial Information Sciences, XXIII ISPRS Congress, Prague, Czech Republic, 12-19 July 2016; Volume III-5.

15. Özdemir, E.; Remondino, F. Segmentation of 3D photogrammetric point cloud for 3D building modeling. Int. Arch. Photogramm. Remote Sens. Spat. Inf. Sci. 2018, XLII-4/W10, 135-142. [CrossRef]

16. Yang, X.; Lu, Y.-C.; Murtiyoso, A.; Koehl, M.; Grussenmeyer, P. HBIM modeling from the surface mesh and its extended capability of knowledge representation. ISPRS Int. J. Geo-Inf. 2019, 8, 301. [CrossRef]

17. Barazzetti, L.; Banf, F.; Brumana, R.; Gusmeroli, G.; Previtali, M.; Schiantarelli, G. Cloud-to-BIM-to-FEM: Structural simulation with accurate historic BIM from laser scans. Simul. Model. Pract. Theory 2015, 57, 71-87. [CrossRef]

18. Gianinetto, M.; Della, T.S. (Eds.) Digital Transformation of the Design, Construction and Management Processes of the Built Environment; Springer: Cham, Switzerland, 2020.

19. Dore, C.; Murphy, M. Historic building information modeling (HBIM). In Handbook of Research on Emerging Digital Tools for Architectural Surveying, Modeling, and Representation; Brusaporci, S., Ed.; IGI Global: Hershey, PA, USA, 2015; pp. $239-279$.

20. Murphy, M.; McGovern, E.; Pavia, S. Historic building information modelling (HBIM). Struct. Surv. 2009, 38, 311-327. [CrossRef]

21. Tucci, G.; Betti, M.; Conti, A.; Corongiu, M.; Fiorini, L.; Matta, C.; Kovačević, C.; Borri, C.; Hollberg, C. BIM for museums: An integrated approach from the building to the collections. Int. Arch. Photogramm. Remote Sens. Spatial Inf. Sci. 2019, XLII-2/W11, 1089-1109. [CrossRef]

22. Cannistraro, M.; Bernardo, E. Monitoring of the indoor microclimate in hospital environments a case study the Papardo hospital in Messina. Int. J. Heat Technol. 2017, 35, S456-S465. [CrossRef]

23. Bernardo, E.; Bilotta, G. Monumental Arc 3D Model Reconstruction through BIM Technology. In New Metropolitan Perspectives. NMP 2020. Smart Innovation, Systems and Technologies; Bevilacqua, C., Calabrò, F., Della Spina, L., Eds.; Springer: Cham, Switzerland, 2021; Volume 178. [CrossRef]

24. Barrile, V.; Fotia, A.; Bernardo, E.; Bilotta, G. Geomatic Techniques: A Smart App for a Smart City. In New Metropolitan Perspectives. NMP 2020. Smart Innovation, Systems and Technologies; Bevilacqua, C., Calabrò, F., Della Spina, L., Eds.; Springer: Cham, Switzerland, 2021; Volume 178. [CrossRef]

25. Brumana, R.; Della Torre, S.; Oreni, D.; Cantini, L.; Previtali, M.; Barazzetti, L.; Banfi, F. SCAN to HBIM-Post Earthquake Preservation: Informative Model as Sentinel at the Crossroads of Present, Past, and Future. In Digital Heritage. Progress in Cultural Heritage: Documentation, Preservation, and Protection. EuroMed; Ioannides, M., Fink, E., Brumana, R., Patias, P., Doulamis, A., Martins, J., Wallace, M., Eds.; Springer: Cham, Switzerland, 2018; Volume 11196. [CrossRef]

26. Funari, M.F.; Hajjat, A.E.; Masciotta, M.G.; Oliveira, D.V.; Lourenço, P.B. A Parametric Scan-to-FEM Framework for the Digital Twin Generation of Historic Masonry Structures. Sustainability 2021, 13, 11088. [CrossRef]

27. Pepe, M.; Costantino, D.; Restuccia Garofalo, A. An Efficient Pipeline to Obtain 3D Model for HBIM and Structural Analysis Purposes from 3D Point Clouds. Appl. Sci. 2020, 10, 1235. [CrossRef] 